\title{
Beneficial effects of a high fibre diet on oocyte maturity and embryo survival in gilts
}

\author{
E M Ferguson, J Slevin ${ }^{1}$, M G Hunter ${ }^{1}$, S A Edwards ${ }^{2}$ and C J Ashworth \\ Sustainable Livestock Systems Group, SAC, Roslin BioCentre, Roslin, Midlothian EH25 9PS, UK ${ }^{1}$ Division of Animal \\ Physiology, University of Nottingham, Sutton Bonington, Leicestershire LE12 5RD, UK and ${ }^{2}$ University of Newcastle, \\ School of Agriculture, Food and Rural Development, Newcastle Upon Tyne NE1 7RU, UK
}

Correspondence should be addressed to C J Ashworth; Email: cheryl.ashworth@sac.ac.uk

E M Ferguson is now at Assisted Reproduction Unit, Department of Obstetrics and Gynaecology, Aberdeen Maternity Hospital, Foresterhill, Aberdeen AB25 2ZO, UK

\begin{abstract}
The present study examined the effects of feeding gilts a high fibre diet from the third post-pubertal oestrus until either day 19 of the same cycle or insemination at the following oestrus on oocyte maturity, embryo survival and associated changes in reproductive hormone concentrations. Gilts fed with the high fibre diet had lower circulating oestradiol concentrations on days 17,18 and 19 of the cycle and increased $\mathrm{LH}$ pulse frequency on day 18 . More oocytes recovered on day 19 from gilts receiving the high fibre diet were at metaphase II after 46-h culture in medium containing $10 \%$ of their own follicular fluid, despite fewer large $(>7 \mathrm{~mm})$ follicles in these gilts when compared with control animals. There was no effect of diet on ovulation rate, corpora lutea size or progesterone concentrations on days 10-12 after insemination, but embryo survival on days 27-29 after insemination was higher in gilts that received the high fibre diet. This study demonstrates that a high fibre diet that increases embryo survival also improves oocyte maturity and provides information on endocrine correlates that may shed light on underlying mechanisms.

Reproduction (2007) 133 433-439
\end{abstract}

\section{Introduction}

Approximately $30 \%$ of oocytes shed at ovulation are not represented by piglets at birth, which is inefficient and a source of economic loss for the pig industry. Most of this prenatal loss occurs during the first month of pregnancy. There is increasing evidence that the diet consumed before mating can have a major impact on embryo survival (Zak et al. 1997, Ashworth et al. 1999a, Ferguson et al. 2006), within litter uniformity in blastocyst size (Ashworth et al. 1999b) and the incidence of runting (Ferguson et al. 2006) in pigs.

In contrast to earlier reports that assessed the impact of altered amounts (typically multiples of maintenance rations) of feed intake, our recent study demonstrated that alterations in the content of the diet fed before mating enhanced embryo survival in the pig. Specifically, feeding a high fibre diet during the oestrous cycle preceding mating increased embryo survival and reduced the number of litters containing intra-uterine growth retarded fetuses on day $27 \pm 2$ of pregnancy when compared with controls (Ferguson et al. 2006). The mechanisms underlying these important benefits of a high fibre diet on embryo survival clearly warrant further study.
It is likely that the beneficial effects of diet during this premating period are mediated through alterations in the ovarian follicle in which the oocyte matures. There is a growing body of evidence that altered nutritional regimens prior to mating can influence oocyte/follicle characteristics (Zak et al. 1997, Quesnel et al. 1998, Yang et al. 2000, Ferguson et al. 2003). For example, we found that a high feed intake enhanced oocyte nuclear maturation by increasing the percentage of oocytes that reached metaphase II in vitro and changed follicular fluid composition (Ferguson et al. 2003), providing evidence of a link between dietary intake and oocyte maturity. The results also indicated that improved oocyte quality was associated with a number of changes in reproductive and metabolic hormones, including lower circulating concentrations of oestradiol and progesterone in gilts fed with the high intake diet. This was accompanied by an increase in the number of luteinizing hormone (LH) pulses presumably through reduced negative feedback on the hypothalamic/pituitary axis. Thus, a decreased concentration of circulating steroids may be one of the hormonal mechanisms responsible for improved oocyte maturation rates. 
There is evidence, from both in vivo and in vitro studies, that dietary fibre reduces circulating steroid concentrations. In vitro oestrogens have been shown to bind to a variety of fibre sources (Arts et al. 1991a). If a similar phenomenon occurs in vivo, this would be expected to lower circulating oestrogen levels by interruption of the enterohepatic circulation. The objectives of the present study were to investigate the hormonal and ovarian mechanisms by which the high fibre diet improves embryo survival in the pig. The hypothesis was tested that embryo survival was increased as a result of enhanced oocyte maturation caused by high fibre dietary induced changes in circulating levels of preovulatory steroids. Gilts were fed with the high fibre or a control diet prior to mating, blood samples collected and either follicles and oocytes recovered before ovulation, or animals were inseminated and embryo survival was assessed on days 27-29 of pregnancy.

\section{Materials and Methods}

\section{Experimental animals}

All animal procedures were conducted at Scottish Agricultural College Aberdeen in accordance with the UK Animals (Scientific Procedures) Act, 1986, following local ethical approval.

This study used $45 \quad F_{1}$ Large White $\times$ Landrace crossbred gilts obtained from JSR Healthbred Ltd (Driffield, UK) at an average age and weight of 146 days and $74.9 \mathrm{~kg}$ respectively. Puberty occurred at an average weight of $92.8 \pm 1.01 \mathrm{~kg}$. Gilts were group housed on straw throughout the study except during recovery from surgery and during frequent blood sampling, when they were penned individually. A schematic diagram outlining the experimental design is presented in Fig. 1. All gilts were individually fed $2.3 \mathrm{~kg} /$ day of a complete diet supplying $15.1 \%$ crude protein and $9.74 \mathrm{MJ}$ net energy $(\mathrm{NE}) / \mathrm{kg}$ until the beginning of the third oestrous cycle. Gilts were randomly assigned to receive either $2.4 \mathrm{~kg} /$ day of a $1.8 \times \mathrm{M}$ (maintenance) control diet supplying $15.1 \%$ crude protein and $9.74 \mathrm{MJ} \mathrm{NE} / \mathrm{kg}(n=22)$ or $2.8 \mathrm{~kg} /$ day of a high fibre diet supplying $14.0 \%$ crude protein and $8.38 \mathrm{MJ} \mathrm{NE} / \mathrm{kg}(n=23)$ containing $50 \%$ unmolassed sugar beet pulp, as described by Ferguson et al. (2006), to supply the same daily NE intake (23.4 MJ). Experimental diets were given during the third oestrous cycle, from the day after the first detection of oestrus (day 1 ; oestrus $=$ day $0)$ until either slaughter on day 19 ( $n=12$ gilts per dietary treatment) or until insemination at the following oestrus. The remaining gilts from each dietary treatment were inseminated from the beginning of their fourth oestrus and thereafter, twice daily throughout oestrus. These gilts received $2.5 \mathrm{~kg} /$ day of the complete diet from insemination until slaughter on days 27-29.

Gilts were examined once each day for the onset of standing oestrus before puberty and during subsequent oestrous cycles by direct exposure to a vasectomised boar for $15 \mathrm{~min}$. After one oestrous cycle of normal duration (19-22 days), oestrous cycles were synchronised by administration of the synthetic progestagen altrenogest (Regumate, Janssen Animal Health, Saunderton, High Wycombe, Buckinghamshire, UK) during the second oestrous cycle. Altrenogest was administered via spray application on the feed ration for at least 25 days beginning around day 9 .

Between days 2 and 13 of the second oestrous cycle 44 gilts (22 from each dietary regimen) underwent surgical insertion of a cannula and vascular access port under general anaesthesia. Gilts received an i.m. injection of ketamine $(6.5 \mathrm{mg} / \mathrm{kg})$ and stresnil $(1.0 \mathrm{mg} / \mathrm{kg}$ containing $600 \mu \mathrm{g}$ atrophine) approximately 30 min before induction of anaesthesia. Anaesthesia was induced with ketamine $(2.0 \mathrm{mg} / \mathrm{kg})$ and midazolam (hypnovel, $0.037 \mathrm{mg} / \mathrm{kg}$ ) by injection into an ear vein via a butterfly needle. Anaesthesia was maintained with $\mathrm{O}_{2}$ and $\mathrm{N}_{2} \mathrm{O}$ in a $1: 2$ ratio and halothane at $1.5-2 \%$ via an endotrachael tube. The cannula and vascular access port were inserted and maintained as described by Ferguson et al. (2003) except that each gilt also received an i.m. injection of depomycin forte $(200 \mathrm{mg}$ pen/strep per $45 \mathrm{~kg})$ and finadyne $(1 \mathrm{ml} / 45 \mathrm{~kg})$ close to the site of cannula insertion. Food was withheld for $24 \mathrm{~h}$ before surgery, but all gilts received feed and regumate in the evening after surgery.

\section{Body weight and scanning}

All gilts were weighed and their backfat thickness measured at puberty, at the onset of the third oestrous

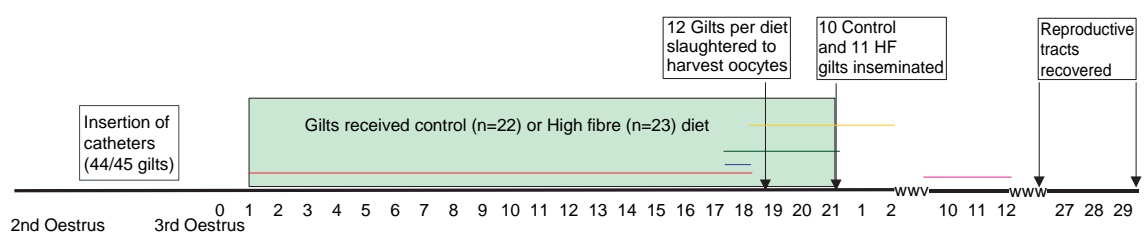

Figure 1 Schematic diagram showing dietary treatments and sample recovery times. (Red) daily blood sample collection from all gilts, (Blue) blood samples collected from all catheterised gilts every $15 \mathrm{~min}$ for $8 \mathrm{~h}$ to measure $\mathrm{LH}$ pulses, (Green) blood samples collected from catheterised gilts in insemination groups every $4 \mathrm{~h}$ to monitor oestradiol peak, (Yellow) blood samples collected from catheterised gilts in insemination groups every $2 \mathrm{~h}$ to monitor LH surge and (Pink) daily blood samples collected from catheterised inseminated gilts to monitor progesterone levels. 
cycle, on day 18 of the treatment cycle and, in the case of inseminated gilts, at slaughter. Backfat thickness was measured at the P2 position using an ultrasound probe (Aloka Holding Europe AG, Zug, Switzerland).

\section{Collection of blood samples}

Daily blood samples were collected from all cannulated gilts at approximately $2 \mathrm{~h}$ after an 0800 feed from days 1 to 18 of the treatment cycle to determine plasma steroid profiles. The blood sampling regimen is shown in Fig. 1. Briefly, on day 18 , blood samples were collected from all gilts every $15 \mathrm{~min}$ for $8 \mathrm{~h}$ to measure $\mathrm{LH}$ pulses. A single preslaughter blood sample was obtained from gilts slaughtered on day 19 to estimate oestradiol concentrations. In gilts destined to be inseminated, blood samples were collected every $4 \mathrm{~h}$ from day 18 of the treatment cycle until day 0 of the next cycle to monitor the oestradiol peak, and every $2 \mathrm{~h}$ from day 19 until day 2 after insemination to monitor the $\mathrm{LH}$ surge. Daily samples were also collected from inseminated gilts on days 10,11 and 12 to measure progesterone concentrations during pregnancy. Blood samples were collected in heparised tubes and centrifuged at $2200 \mathrm{~g}$ for $10-15 \mathrm{~min}$. Plasma was removed and stored at $-20{ }^{\circ} \mathrm{C}$.

\section{Ovary and oocyte recovery}

Twelve gilts from each of the two feeding regimens were slaughtered at a local abattoir on day 19 of the treatment cycle and their ovaries transported to the laboratory. Oocytes were processed as described by Ferguson et al. (2003), except that, wherever possible, oocytes were recovered from the largest 16 or 15 follicles from each gilt fed with the control or high fibre diet respectively. These numbers reflect the mean ovulation rates observed in our previous study using the same gilt genotype and nutritional regimens (Ferguson et al. 2006) and are therefore considered to reflect the ovulatory population in both groups. Follicular size was measured, follicular fluid collected, oocyte cumulus complexes matured in $10 \%$ of the gilts' own follicular fluid and assessed as described by Ferguson et al. (2003).

\section{Recovery of pregnant reproductive tract}

Inseminated gilts were slaughtered on days 27-29 of pregnancy and the reproductive tracts removed. Gravid reproductive tracts were dissected to count numbers of corpora lutea and fetuses. Fetuses were considered viable if there was no visible necrosis and the amniotic fluid was not haemolysed. Embryo survival was calculated as the percentage of corpora lutea represented by a viable fetus.

\section{Plasma analysis}

\section{$L H$}

Plasma concentrations of $\mathrm{LH}$ were measured in duplicate by a double antibody RIA as described by Rensis et al. (1993). The limit of sensitivity of the assay was $0.13 \mathrm{ng} / \mathrm{ml}$. The intra- and inter-assay coefficients of variation were 11.9 and $16.6 \%$ respectively.

\section{Progesterone}

Plasma progesterone concentrations were determined in duplicate by petroleum ether extraction prior to RIA with ${ }^{125} \mathrm{I}$ using the method described by Hunter et al. (1986). The limit of sensitivity was $0.66 \mathrm{ng} / \mathrm{ml}$ and the intra- and inter-assay coefficients of variation were 8.5 and $11.8 \%$ respectively.

\section{Oestradiol}

Oestradiol concentrations were determined in plasma samples obtained from all gilts on days 1, 6, 12, 15, 16, 17 , and 18 after oestrus. Oestradiol concentrations were measured after diethyl ether extraction using a RIA kit (E2 MAIA Serono Diagnostics, Woking, UK) as described and validated for porcine plasma by Hunter et al. (1996). The limit of sensitivity was $1.14 \mathrm{pg} / \mathrm{ml}$. The intra- and inter-assay coefficients of variation were 14.3 and $17.8 \%$ respectively.

\section{Oestradiol in follicular fluid}

Oestradiol concentrations in follicular fluid were measured without extraction. The $\left[{ }^{125} \mathrm{I}\right]$ oestradiol RIA was based on the method of Webb et al. (1985). The limit of sensitivity was $216 \mathrm{pg} / \mathrm{ml}$ and the mean intra- and inter-assay coefficients of variation were 7.7 and $10.1 \%$ respectively.

\section{Statistical analysis}

Data from 2 out of the 44 cannulated gilts were excluded from analysis. Both gilts were assigned to receive the high fibre diet and to be inseminated. One gilt failed to show a third oestrus and in the other, the time taken to reach peak oestradiol concentrations prior to insemination was unusually long (102 h, compared with a range between 18 and $54 \mathrm{~h}$ in other gilts). LH pulses were defined as described previously (Ferguson et al. 2003). All data were analysed using the Genstat statistical package (Genstat 8: Committee of the Statistics Department, Rothamsted Experimental Station, Harpenden, Hertfordshire, UK). All dependent variables were checked for normality using histogram plots. Only data from gilts that were pregnant at slaughter were included in the analyses of progesterone concentrations on days 10-12 after insemination, and of luteal weight and size. Plasma concentrations of oestradiol and progesterone 
were analysed by repeated measures and comparisons on individual days analysed by $t$-tests. Mean gilt values for follicle size, volume and oestradiol content and for luteal weight and size were calculated and effects of diet on these values and all other variables measured were determined by ANOVA. Differences were considered statistically significant when $P<0.05$.

\section{Results}

There was no treatment effect on backfat or weight change, except that gilts receiving the high fibre diet were heavier after 18 days of this dietary regimen (Table 1 ). This probably reflects increased gut fill as a consequence of the high fibre diet as there was no associated increase in backfat thickness, and the weight difference disappeared after a subsequent period of standard feeding.

Pregnancy rate was $100 \%$ (10 out of 10$)$ for control gilts and $78 \%$ (7 out of 9 ) for high fibre gilts. The mean oestrous cycle length for control and high fibre gilts was $21.0 \pm 0.41$ and $21.4 \pm 0.40$ days respectively.

Cannulae in two gilts from each of the two feeding regimens did not remain patent long enough to obtain reliable preovulatory hormone profiles. It was not possible to determine the time of the $\mathrm{LH}$ surge from an additional gilt in the high fibre group. Comparisons of hormone profiles from all gilts studied revealed a significant effect of diet $(P<0.01)$ and of the day $\times$ diet interaction $(P<0.01)$ on plasma oestradiol concentrations (Fig. 2). Oestradiol concentrations in gilts fed with the high fibre diet were significantly lower than control-fed gilts on days $17(P<0.01)$ and $18(P<0.001)$. Overall, there was neither a significant day $\times$ diet interaction, nor a significant effect of diet, on circulating progesterone concentrations (Fig. 3). Analyses of dietary effects on individual days indicated that on day 13 progesterone levels in gilts fed with the high fibre diet were significantly lower than control-fed gilts $(13.60 \pm 0.85$ vs $17.39 \pm 0.85 \mathrm{ng} / \mathrm{ml}$ respectively; $P=0.023)$. Gilts fed with the high fibre diet had more LH pulses during an 8-h sampling period on day 18 than control-fed gilts $(3.3 \pm 0.18(n=19)$ vs $2.6 \pm 0.19(n=20)$ respectively; $P=0.016$ ).

Table 1 Weight and back fat thickness of gilts over the experimental period.

\begin{tabular}{|c|c|c|c|}
\hline & Control & High fibre & Significance \\
\hline \multicolumn{4}{|l|}{ Weight (kg) } \\
\hline Prior to experimental diet* & $118.8 \pm 0.85$ & $119.7 \pm 1.17$ & ns \\
\hline Day 18 of treatment cycle* & $128.9 \pm 1.19$ & $133.6 \pm 1.24$ & $P=0.011$ \\
\hline Days $27-29$ after insemination ${ }^{+}$ & $145.0 \pm 2.07$ & $143.3 \pm 2.23$ & ns \\
\hline \multicolumn{4}{|l|}{ Back fat thickness (mm) } \\
\hline Prior to experimental diet* & $16.2 \pm 0.15$ & $16.3 \pm 0.12$ & ns \\
\hline Day 18 of treatment cycle* & $17.8 \pm 0.17$ & $17.7 \pm 0.15$ & ns \\
\hline Days $27-29$ after insemination ${ }^{+}$ & $19.4 \pm 0.22$ & $19.2 \pm 0.28$ & ns \\
\hline
\end{tabular}

Values are mean \pm S.E.M. of $* 22$ and ${ }^{\dagger} 10$ control gilts and ${ }^{*} 21$ and ${ }^{\dagger} 9$ high fibre-fed gilts.

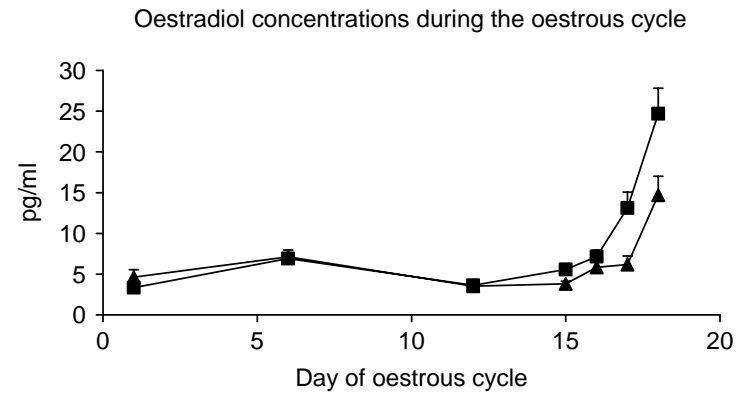

Figure 2 Mean \pm s.E.M. circulating oestradiol concentrations in gilts fed with either a control $\mathbf{\square}(n=22)$ or a high fibre $\boldsymbol{\Lambda}(n=20)$ diet during the oestrous cycle. Plasma oestradiol concentrations were significantly lower on days 17 and 18 in gilts fed with the high fibre diet when compared with those fed with the control diet.

There was no effect of dietary treatment on peak concentrations of LH or oestradiol. Furthermore, dietary treatment did not affect the interval between the beginning of intensive blood sample collection and peak values of either hormone, or the interval between the fall in progesterone (defined as the first day when progesterone concentrations were below $10 \mathrm{ng} / \mathrm{ml}$ ) and peak values (Table 2).

Gilts receiving the high fibre diet had fewer large follicles and lower follicular fluid volumes (Table 3) when compared with gilts fed with the control diet. Despite fewer large follicles in gilts fed with the high fibre diet, more oocytes recovered from these gilts were in metaphase II after culture (Table 4).

The high fibre diet did not affect the number or size of corpora lutea, but did increase the percentage of corpora lutea represented by a viable fetus (Table 5).

\section{Discussion}

We recently reported that feeding a high fibre diet to gilts prior to mating increases embryo survival (Ferguson et al. 2006). The present study confirms this finding and

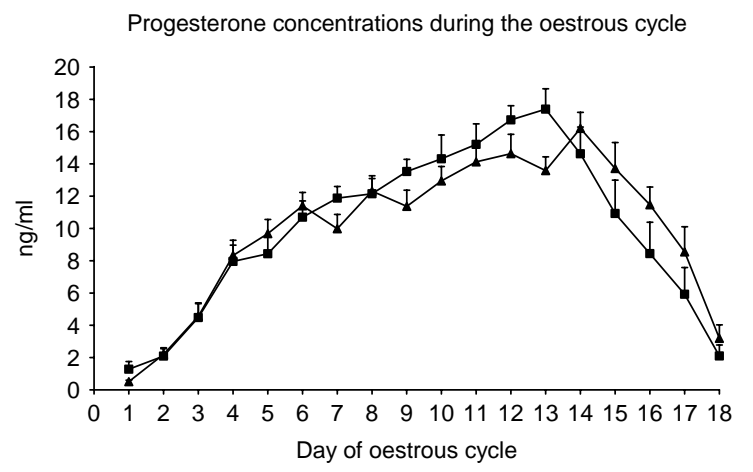

Figure 3 Mean \pm S.E.M. circulating progesterone concentrations in gilts fed with either a control $\mathbf{\square}(n=22)$ or a high fibre $\boldsymbol{\Lambda}(n=20)$ diet during the oestrous cycle. Plasma progesterone concentrations were significantly lower on day 13 in gilts fed with the high fibre when compared with the control diet. 
Table 2 Periovulatory hormone concentrations in gilts fed with either a control or a high fibre diet since oestrus.

\begin{tabular}{|c|c|c|c|}
\hline & Control & High fibre & Significance \\
\hline \multicolumn{4}{|l|}{ Oestradiol } \\
\hline Peak value (pg/ml) & $33.0 \pm 3.8$ & $34.2 \pm 5.1$ & NS \\
\hline $\begin{array}{l}\text { Time to peak value } \\
\text { from } 1000 \mathrm{~h} \text { on day } 18(\mathrm{~h})\end{array}$ & $28.2 \pm 5.31$ & $34.8 \pm 6.11$ & NS \\
\hline $\begin{array}{l}\text { Time to peak value } \\
\text { after progesterone } \\
<10 \mathrm{ng} / \mathrm{ml}(\mathrm{h})\end{array}$ & $94.25 \pm 13.95$ & $87.6 \pm 11.63$ & NS \\
\hline \multicolumn{4}{|l|}{$\mathrm{LH}$} \\
\hline Peak value (ng/ml) & $8.0 \pm 1.10$ & $6.20 \pm 1.27$ & NS \\
\hline $\begin{array}{l}\text { Time to start of LH } \\
\text { surge from } 1200 \mathrm{~h} \\
\text { on day } 19(\mathrm{~h})\end{array}$ & $44.3 \pm 8.30$ & $46.0 \pm 8.12$ & NS \\
\hline Time to peak value $(\mathrm{h})$ & $50.0 \pm 8.45$ & $56.8 \pm 7.16$ & NS \\
\hline $\begin{array}{l}\text { Time to peak value } \\
\text { after progesterone } \\
<10 \mathrm{ng} / \mathrm{ml}(\mathrm{h})\end{array}$ & $116.67 \pm 9.66$ & $109.6 \pm 16.57$ & NS \\
\hline
\end{tabular}

Values are mean \pm S.E.M. of eight control and five high fibre gilts.

demonstrates that this nutritional regimen also improves oocyte maturity and alters preovulatory endocrinology. These are believed to be the first data showing that a dietary modification, rather than an altered amount of feed, that increases embryo survival also improves oocyte maturity in the gilt, and to provide evidence of the endocrine correlates of these reproductive benefits. The results support the hypothesis that appropriate preovulatory development is a major determinant of subsequent embryo survival in the pig.

It is likely that the effect of altered nutrition on oocyte maturity and ultimately embryo survival is mediated by changes in circulating concentrations of key reproductive hormones and by changes in the environment within the ovarian follicle.

Increased feed intake also improves oocyte quality and embryo survival in sows and gilts (Zak et al. 1997, Ashworth et al. 1999a, Ferguson et al. 2003). In the present study, and in the study described by Ferguson et al. (2003), where intake was increased, improved oocyte maturity was associated with increased LH pulse

Table 3 Plasma oestrogen concentrations and ovarian development in gilts slaughtered on day 19 having received either a control or a high fibre diet since oestrus.

\begin{tabular}{lccc}
\hline & Control & High fibre & Significance \\
\hline Plasma oestradiol $(\mathrm{pg} / \mathrm{ml})$ & $28.42 \pm 9.61$ & $7.15 \pm 0.91$ & 0.048 \\
Ovarian weight $(\mathrm{g})$ & $14.8 \pm 0.92$ & $14.7 \pm 0.39$ & $\mathrm{NS}$ \\
Mean follicle diameter $(\mathrm{mm})$ & $6.53 \pm 0.55$ & $5.24 \pm 0.33$ & $\mathrm{NS}$ \\
$\%$ Small follicles $(<5 \mathrm{~mm})$ & $39.2 \pm 11.80$ & $61.5 \pm 11.29$ & $\mathrm{NS}$ \\
$\%$ Medium follicles $(>5 \mathrm{~mm}$, & $22.4 \pm 6.70$ & $28.4 \pm 8.23$ & $\mathrm{NS}$ \\
$<7 \mathrm{~mm})$ & & & \\
$\%$ Large follicles $(>7 \mathrm{~mm})$ & $38.3 \pm 11.99$ & $9.3 \pm 4.79$ & 0.05 \\
Follicular fluid volume $(\mu \mathrm{l})$ & $108.65 \pm 16.31$ & $62.93 \pm 7.37$ & 0.018 \\
Follicular fluid oestradiol $(\mathrm{ng} / \mathrm{ml})$ & $127.86 \pm 33.61$ & $74.0 \pm 11.84$ & $\mathrm{NS}$ \\
\hline
\end{tabular}

Values are mean \pm S.E.M. of 12 gilts per treatment group. Plasma oestradiol concentrations are from the 12 gilts/treatment slaughtered on day 19.
Table 4 Nuclear maturation of oocytes recovered on day 19 in gilts fed with either a control or a high fibre diet since oestrus.

\begin{tabular}{lccc}
\hline & Control & High fibre & Significance \\
\hline Total no. of follicles dissected & 184 & 179 & \\
$\begin{array}{l}\text { Average no. of follicles } \\
\text { dissected/gilt }\end{array}$ & $14.9 \pm 0.08$ & $15.3 \pm 0.31$ & \\
Total number of oocytes fixed & 161 & 162 & \\
$\begin{array}{l}\text { Germinal vesicle (\%) } \\
\text { Germinal vesicle breakdown }\end{array}$ & $1.85 \pm 0.97$ & $1.24 \pm 0.83$ & $\mathrm{NS}$ \\
$(\%)$ & & & \\
Metaphase I (\%) & $25.25 \pm 2.99$ & $20.1 \pm 2.25$ & $\mathrm{NS}$ \\
$\begin{array}{l}\text { Metaphase II (\%) } \\
\text { Total \% unidentified/ }\end{array}$ & $65.66 \pm 2.88$ & $75.73 \pm 1.68$ & 0.006 \\
degenerated or lost & $5.50 \pm 1.94$ & $1.88 \pm 1.34$ & $\mathrm{NS}$ \\
\hline
\end{tabular}

Values are mean \pm S.E.M. of 12 gilts per treatment group.

frequency. It is likely that the increase in $\mathrm{LH}$ pulse frequency arises as a consequence of lower circulating steroid concentrations providing reduced negative feedback to the hypothalamus. Studies involving altered feed intake have consistently reported an inverse relationship between the plane of nutrition and circulating steroid concentrations in the pig (Dyck et al. 1980, Ferguson etal. 2003). This relationship is thought to be attributed to increased steroid metabolism arising from increases in hepatic size, hepatic mixed function oxidase activity and portal blood-flow in well-fed animals (Prime \& Symonds 1993, Ashworth et al. 1999a). In the case of the high fibre diet used in the present study, the reduced circulating oestradiol concentrations observed are more probably due to interruption of enterohepatic circulation. There is evidence from both in vivo and in vitro studies that dietary fibre reduces steroid concentrations. In vitro oestrogens have been shown to bind to a variety of fibre sources (Arts et al. 1991a). In vivo studies report increased faecal excretion of both free and conjugated oestrogens in rats fed with a high fibre diet (Arts et al. 1991 b), and inverse relationships between dietary fibre content and plasma oestrogen concentrations in women (Rose et al. 1991). Our present working hypothesis proposes that the high fibre diet promotes increased removal of circulating steroid, possibly by binding of steroid to fibre in the gut or

Table 5 Numbers of corpora lutea and fetuses on days $27-29$ of pregnancy in gilts fed with either a control or a high fibre diet during the oestrous cycle preceding insemination.

\begin{tabular}{lccc}
\hline & Control & High fibre & Significance \\
\hline $\begin{array}{l}\text { Mean plasma progesterone } \\
\text { concentrations on days }\end{array}$ & $13.43 \pm 1.09$ & $17.09 \pm 2.42$ & NS \\
$10-12(\mathrm{ng} / \mathrm{ml})^{*}$ & & & \\
Number of corpora lutea $^{\dagger}$ & $16.9 \pm 0.72$ & $16.7 \pm 0.40$ & $\mathrm{NS}$ \\
${\text { Weight of corpora lutea }(\mathrm{g})^{+}}^{+}$ & $0.60 \pm 0.04$ & $0.54 \pm 0.04$ & $\mathrm{NS}$ \\
${\text { Size of corpora lutea }\left(\mathrm{cm}^{2}\right)^{+}}^{+}$ & $2.77 \pm 0.14$ & $2.50 \pm 0.16$ & $\mathrm{NS}$ \\
Number of viable fetuses $^{+}$ & $12.4 \pm 0.97$ & $14.7 \pm 0.87$ & NS \\
\% Embryo survival $^{+}$ & $73.2 \pm 4.90$ & $91.2 \pm 3.23$ & 0.021 \\
\hline
\end{tabular}

Values are mean \pm S.E.M. of $* 7$ and ${ }^{+} 10$ control-fed gilts and $* 5$ and ${ }^{+} 7$ high fibre-fed gilts. 
modified bacterial enzyme activity and interrupted enterohepatic circulation of oestrogen (Arts et al. 1992). The lower circulating oestradiol concentrations reduce the negative feedback effects of oestradiol on the hypothalamic-pituitary axis, increasing the number of LH pulses and hence gonadotrophic support to the ovary as indicated by increased oocyte maturity observed.

The way in which an altered LH profile influences oocyte maturity is uncertain, but it may alter the composition of follicular fluid. Some studies describing nutritionally induced alterations in oocyte quality report a positive relationship between oocyte maturity and follicular fluid oestradiol concentrations (Yang et al. 2000, Ferguson et al. 2003), whereas others (Zak et al. 1997, the present study) do not. The reason for these apparent inconsistencies is unclear, but in the present study, may reflect differences between the dietary treatments in the timing of events during the oestrous cycle. Although gilts receiving each diet were slaughtered at the same chronological stage, they appeared to be at a different physiological stage of the oestrous cycle. Evidence for this comes from the lower circulating oestradiol concentrations on days 17, 18 and 19 and the fewer large ovarian follicles and reduced follicular fluid volume on day 19 in gilts fed with the high fibre diet. It is intriguing that gilts receiving the high fibre diet had more mature oocytes, despite the fact that they were recovered from a population with fewer large follicles and follicles with smaller fluid volumes. These results suggest that factors other than follicular oestrogen may have been influenced by $\mathrm{LH}$ to benefit oocyte development. There are a number of possible candidates produced in the porcine ovary, by both granulosa and theca cells, that can influence oocyte quality, including members of the IGF and the TGF $\beta$ superfamily (Hammond et al. 1993, Brankin et al. 2005). The expression of which of these factor(s) may have been modified by the altered LH pulsatile secretion pattern in the present study clearly requires further study.

We have demonstrated a repeatable method to improve embryo survival in the pig that does not involve increased feed level and has achieved an average benefit of an extra 0.96 piglet per litter when tested in a commercial environment (Ferguson et al. 2004). The mechanism appears to involve dietary-induced alterations in oestradiol and $\mathrm{LH}$ profiles that enable more oocytes to reach maturity prior to ovulation. This provides further evidence of the importance of the preovulatory environment to increase embryo survival and eventual litter size.

\section{Acknowledgements}

Funded by Defra, MLC and JSR Farms Ltd in the Link Sustainable Livestock Production Programme. The authors thank M Phillippo for anaesthesia, $\mathrm{R}$ Walker for advice on surgical procedures, D Dolman, R Watt and A Walker for skilled assistance with animal work and C Mayer, BioSS, for advice on statistical analyses. Regumate was a generous gift from Janssen Animal Health. SAC receives funding from the Scottish Executive, Environment and Rural Affairs Department. The authors declare that there is no conflict of interest that would prejudice the impartiality of this scientific work.

\section{References}

Arts CJM, Govers CAR, van den Berg H, Wolters MGE, van Leeuwen P \& Thijssen JHH 1991a In vitro binding of estrogens by dietary fiber and the in vivo apparent digestability tested in pigs. Journal of Steroid Biochemistry and Molecular Biology 38 621-628.

Arts CJ, de Bie AT, van den berg H, van't Veer P, Bunnik GS \& Thijssen JH 1991b Influence of wheat bran on NMU-induced mammary tumor development, plasma estrogen levels and estrogen excretion in female rats. Journal of Steroid Biochemistry and Molecular Biology 39 193-202.

Arts CJ, Govers CA, van den Berg H, Blankenstein MA \& Thijssen JH 1992 Effect of wheat bran on excretion of radioactively labeled estradiol-17 beta and estrone-glucuronide injected intravenously in male rats. Journal of Steroid Biochemistry and Molecular Biology 42 103-111.

Ashworth CJ, Antipatis C \& Beattie L 1999a Effects of pre- and postmating nutritional status on hepatic function, progesterone concentration, uterine protein secretion and embryo survival in Meishan pigs. Reproduction, Fertility, and Development 11 67-73.

Ashworth CJ, Beattie L, Antipatis C \& Vallet J $1999 \mathrm{~b}$ Effects of pre- and post-mating feed intake on blastocyst size, secretory function and glucose metabolism in Meishan gilts. Reproduction, Fertility, and Development 11 323-327.

Brankin V, Quinn RL, Webb R \& Hunter MG 2005 Evidence for a functional bone morphogenic protein system in the porcine ovary. Domestic Animal Endocrinology 28 367-379.

Dyck GW, Palmer WM \& Simaraks S 1980 Progesterone and luteinizing hormone concentration in serum of pregnant gilts on different levels of feed consumption. Canadian Journal of Animal Science 60 844-877.

Ferguson EM, Ashworth CJ, Edwards SA, Hawkins N, Hepburn N \& Hunter MG 2003 Effect of different nutritional regimens before ovulation on plasma concentrations of metabolic and reproductive hormones and oocyte maturation in gilts. Reproduction 126 61-71.

Ferguson EM, Ashworth CJ, Hunter MG, Penny P, Slevin J \& Edwards SA 2004 The effect of feeding a high fibre diet from mid lactation until breeding on subsequent litter size of sows. In The Appliance of Pig Science, pp 175-179. Eds JE Thompson, BP Gill \& MA Varley: Nottingham University Press, Nottingham, UK.

Ferguson EM, Slevin J, Edwards SA, Hunter MG \& Ashworth CJ 2006 Effect of alterations in the quantity and composition of the premating diet on embryo survival and foetal growth in the pig. Animal Reproduction Science 96 89-103.

Hammond JM, Samaras SE, Grimes R, Leighton J, Barber J, Canning SF \& Guthrie HD 1993 The role of insulin-like growth factors and epidermal growth factor-related peptides in intraovarian regulation in the pig ovary. Journal of Reproduction and Fertility Supplement 48 117-125.

Hunter MG, Southee JA, McLeod M \& Haresign W 1986 Progesterone pre-treatment has a direct effect on $\mathrm{GnRH}$-induced preovulatory follicles to determine their ability to develop into normal corpora lutea in anoestrous ewes. Journal of Reproduction and Fertility $\mathbf{7 6}$ 349-363.

Hunter MG, Picton HM, Biggs C, Mann GE, McNeilly AS \& Foxcroft GR 1996 Periovulatory endocrinology in high ovulating Meishan sows. Journal of Endocrinology 150 141-147. 
Prime GR \& Symonds HW 1993 Influence of plane of nutrition on portal blood flow and the metabolic clearance rate of progesterone in ovariectomised gilts. Journal of Agricultural Science 121 389-397.

Quesnel H, Prasquier A, Mounier A \& Prunier A 1998 Influence of feed restriction during lactation on gonadotrophic hormones and ovarian development in primiparous sows. Journal of Animal Science $\mathbf{7 6}$ 856-863.

Rensis FD, Hunter MG \& Foxcroft GR 1993 Suckling-induced inhibition of luteinizing hormone secretion and follicular development in the early postpartum sow. Biology of Reproduction 48 964-969.

Rose DP, Goldman M, Connolly JM \& Strong LE 1991 High-fiber diet reduces serum estrogen concentrations in premenopausal women. American Journal of Clinical Nutrition 54 520-525.

Webb R, Baxter G, McBride D, Nordlom GD \& Shaw MPK 1985 The measurement of testosterone and oestradiol $17 \beta$ using iodinated tracers and incorporating an affinity chromatography extraction procedure. Journal of Steroid Biochemistry 23 1043-1051.

Yang H, Foxcroft GR, Pettigrew JE, Johnson LJ, Shurson GC, Costa AN \& Zak LJ 2000 Impact of dietary lysine intake during lactation on follicular development and oocyte maturation after weaning in primiparous sows. Journal of Animal Science 78 993-1000.

Zak LJ, Xu X, Hardin RT \& Foxcroft GR 1997 Impact of different patterns of feed intake during lactation in the primiparous sow on follicular development and oocyte maturation. Journal of Reproduction and Fertility 110 99-106.

Received 2 May 2006

First decision 12 June 2006

Revised manuscript received 29 August 2006

Accepted 10 November 2006 